\title{
DESCRIPTION OF THE METHOD USED BY TOR VERGATA UNIVERSITY OF ROME FOR THE ELECTRONIC FINAL EXAM OF THE DEGREE COURSE IN PHYSIOTHERAPY
}

\author{
Annamaria Servadio ${ }^{1}$, Anna Berardi ${ }^{2}$, Marco Tramontano $^{3}$, Marco Tofani $^{4}$, Rosaria Alvaro ${ }^{5}$, \\ Pasquale Farsetti ${ }^{6}$ and Giovanni Galeoto ${ }^{7}$ \\ ${ }^{I}$ Director of the degree course in physiotherapy, Tor Vergata University of Rome, Tor Vergata Hospital, \\ Viale Oxford, 81, 00133, Rome, Italy \\ ${ }^{2}$ Sapienza University of Rome, Piazzale Aldo Moro 5, 00185, Rome, Italy \\ ${ }^{3}$ Director of the degree course in physiotherapy, Tor Vergata University of Rome, Santa Lucia Foundation IRCCS \\ Via Ardeatina, 306/354, 00179 Rome, Italy \\ ${ }^{4}$ Department of Public Health and Infectious Diseases, Sapienza University, Rome, Italy, Piazzale Aldo Moro 5, \\ 00185, Rome, Italy \\ ${ }^{5}$ Full professor of nursing sciences, coordinator of Bachelor's degrees in the health area, Viale Oxford, 81, \\ 00133, Rome, Italy \\ ${ }^{6}$ Full professor President of the degree course in physiotherapy, Tor Vergata University of Rome, Tor Vergata Hospital, \\ Viale Oxford, 81, 00133, Rome, Italy \\ ${ }^{7}$ Teacher of the degree course in physiotherapy, department of Public Health and Infectious Diseases, Sapienza \\ University, Rome, Italy, Piazzale Aldo Moro 5, 00185, Rome, Italy
}

\begin{abstract}
On 11 March 2020, the Director General of the World Health Organisation (WHO) officially declared the outbreak of the coronavirus (COVID-19) as a pandemic. Much of the global higher-education community has been thrust into an unplanned, unwanted and fraught experiment in online learning. Experts in the academic world must be encouraged to spread and share the strategies they are using to face these challenges. This extraordinary health emergency, which is being experienced in our country and all over the world, has forced Italian universities to modify the organisation of the final tests of their degree courses, including those of the health professions, with the effect of transforming them into online tests. The objective pursued is to not interrupt the completion of university courses by ensuring that students can complete the qualifying exams for these professions. This paper describes the method used at an Italian university to carry out the final exam of the degree course in physiotherapy in electronic form. Final exams have been organised on the basis of the guidance provided at a national level. The technical tool chosen by this university to allow participation in remote exams is the Microsoft Teams platform. The Exam Commission will start the exam, after verifying the environmental requirements in which each candidate wishes to take the exam. At the end of the exam, the President of the Exam Commission will transcribe the names and marks of the student, as well as the names of the members of the Commission on the minutes, and he or she will sign them. This paper represents a first step in the dissemination and sharing, at an academic level, of how one university is dealing with the current situation. It is an important element in helping academics and academia to manage this emergency.
\end{abstract}

\section{KEYWORDS}

COVID-19, e-Learning, Examination, Universities

\section{INTRODUCTION}

On 30 January 2020, the World Health Organisation (WHO) declared the outbreak of the coronavirus (COVID-19) as a Public Health Emergency of International Concern. On 11 March 2020, the WHO's Director General officially declared the outbreak a pandemic and called on "all countries to continue efforts that have been effective in limiting the number of cases and slowing the spread of the virus." (World Health Organisation, 2020) Countries around the world are currently implementing measures to slow the spread of the coronavirus, 
from national quarantines to school closures. Several countries, such as Italy, have imposed restrictions, and the virus has thrust much of the global higher-education community into an unplanned, unwanted and fraught experiment in online learning. For most faculty members and students this is not what they want, but it is what they are being forced to deal with until the end of this academic year.

In Italy, the study path of students enrolled in the degree course in physiotherapy ends with a final exam, the professional qualifying state exam. The exam is organised into two sessions and consists of the following tests:

1. A practical test, during which students must demonstrate that they have acquired a physiotherapist's knowledge and theoretical-practical and operational skills.

2. The preparation of a thesis paper and its dissertation.

The legislation governing the final test defines that, in the practical test, the following skills set out by the Dublin descriptors 2, 3 and 4, built into the Bologna Process, are assessed (European Commission/EACEA/Eurydice, 2018):

- Descriptor 2. Applying knowledge and understanding.

- Descriptor 3. Making judgements.

- Descriptor 4. Communication skills, and, in particular, the ability to identify problems; make decisions on professional problems; identify priorities for individual patients, groups or work processes; plan and decide on interventions on the basis of available evidence and organisational conditions; act safely; consider the ethical, deontological and legal dimensions of their actions; demonstrate an orientation to inter-professional practice and evaluate the outcomes on patients.

The regulatory document also provides that the procedures for carrying out the practical test may include one or more of the following methods (Guidelines for the final test of the Degree Courses belonging to the classes of Health Professions):

- A structured, semi-structured or open-ended written test on paradigmatic cases/situations of professional practice.

- An oral interview with discussion of cases or a project.

- Observation of professional skills (e.g. technical, relational, diagnostic and design) in real clinical contexts, simulated laboratory contexts or with video support - a structured examination of clinical skills.

The health emergency that is being experienced in our country, and all over the world, has forced Italian universities to modify the organisation of the final tests of their degree courses, including those of the health professions, with the effect of enabling the profession to transform its tests into online tests, both for the practical test and for the thesis. The objective is to not interrupt the completion of university courses by ensuring that students can complete the qualifying exams for their profession. This paper describes the method used at an Italian university to carry out the final exam of the degree course in physiotherapy in electronic form.

\section{BODY OF PAPER}

The exams were organized by professionals who was already experienced in managing online courses (Farina, 2019; Paterniani, 2019; Galeoto, 2019a; Galeoto, 2019b). Based on the guidance provided jointly by the Ministry of University and Research (MIUR) and the Italian Ministry of Health (ministerial circular of 30 September 2016) (Directorial Decree n.3478 of 14 April 2020), the final exam, based on the selection of core competencies, can take place following one of the three methods provided. Alternatively, an oral test can be taken involving the discussion and classification of clinical cases or paradigmatic situations of professional practice, with questions by the Commission based on real and/or simulated situations. This choice is in line with what is stated in the standard and can be adapted in a telematic context. Following the above, online tests for the degree in physiotherapy course were organised.

Digital learning management systems, communication tools and e-learning platforms are playing a crucial role during this pandemic. Software and apps can help learning providers to manage, plan, deliver and track the learning process. The United Nations Educational, Scientific and Cultural Organization (UNESCO) has recently published a list of useful tools for this purpose (UNESCO, 2020). The technical tool chosen by the Tor Vergata University of Rome, to allow participation in remote exams, is the Microsoft TEAMS platform. 
To participate, in university email account is required. However, for a better user experience, students are advised to download and install the desktop version of Microsoft Teams, available on different devices or from https://teams.microsoft.com/downloads. Ideally, effective use of the platform requires a personal computer equipped with a video camera and microphone. If access is through the web, it is advisable to use Google Chrome or Microsoft Edge.

For a good-quality video call, the minimum network requirements are $500 \mathrm{kbs}$ (upload)/1Mbps (download). On the day of the exam, an invitation containing a link will be sent via email (to the email address provided to the University during the enrolment phase) to students so they can access the exam's virtual classroom on Microsoft Teams.

Candidates must connect at least 30 minutes before the exam start time, taking care to check that the technical requirements (previously reported) are respected and that they have a valid identity document with them. The Exam Commission, composed by two members designated by the professional college, the MIUR and the Ministry of Health, supervise the regularity of the exam and verifies the candidates' documents.

After verifying the environmental requirements in which the candidates wish to take the exam, the Exam Commission proceeds to the examination. The practical test is conducted through the discussion of a clinical case and related questions from the Commission. The Commission will prepare a number of clinical cases equal to the number of candidates present plus a number of five. On the day of the exam, a clinic case will be drawn for each student and with a Simple Randomization, based on a single sequence of random assignments, the clinical case will be assigned to each student, the cases not extracted must be opened and described at the end of the test. At the end of the exam, the President of the Exam Commission will transcribe the names and marks of the student, as well as the names of the members of the Commission on the minutes, and he or she will sign them. The President of the Exam Commission records the students' marks for the exam.

When conducting remote examinations, several precautions must be taken. The environment in which the exam takes place must be silent and sufficiently illuminated to allow recognition of the candidate, and no other people must be present. Students are asked to position their video camera so that it is framed in "half length," with their hands in the frame so it is easy to verify that they do not have a cell phone or notes from which they can read. Furthermore, candidates must not wear hats and must have their ears uncovered to check for earphones or the like. During their oral presentation, candidates are asked to keep their gaze fixed on the video camera to verify that they do not read from unseen sources. If the connection is lost during the interview, the question is cancelled, and the interview resumes with a new application. In the event that candidates have to write something to answer an exam question (e.g. a formula, chemical reaction or graphic scheme), the video shot must include the support on which the candidates will write, for example, a sheet of white paper. It is advisable to ask candidates to bring the paper closer to the video camera once completed and to also read its contents out loud.

If Microsoft Teams is installed on your PC just click on Open Microsoft Teams (Figure 1). If Microsoft Teams is NOT installed on your PC click on Join the Web (Figure 1). The following screen will appear, where you will be asked to enter your name and then, by clicking on Join now, you will enter the meeting (Figure 2).

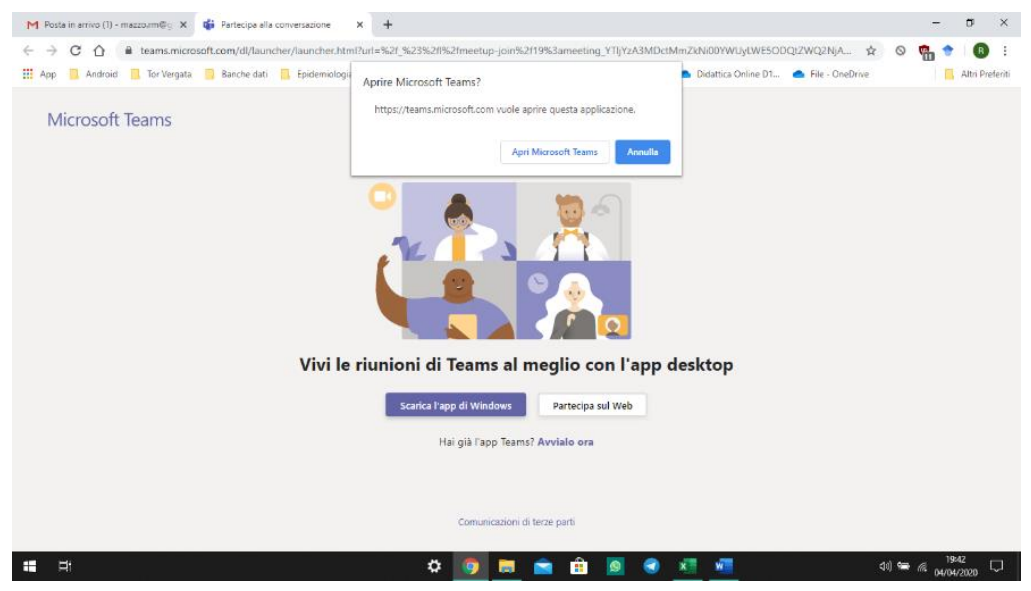

Figure 1. Microsoft Teams, front page 


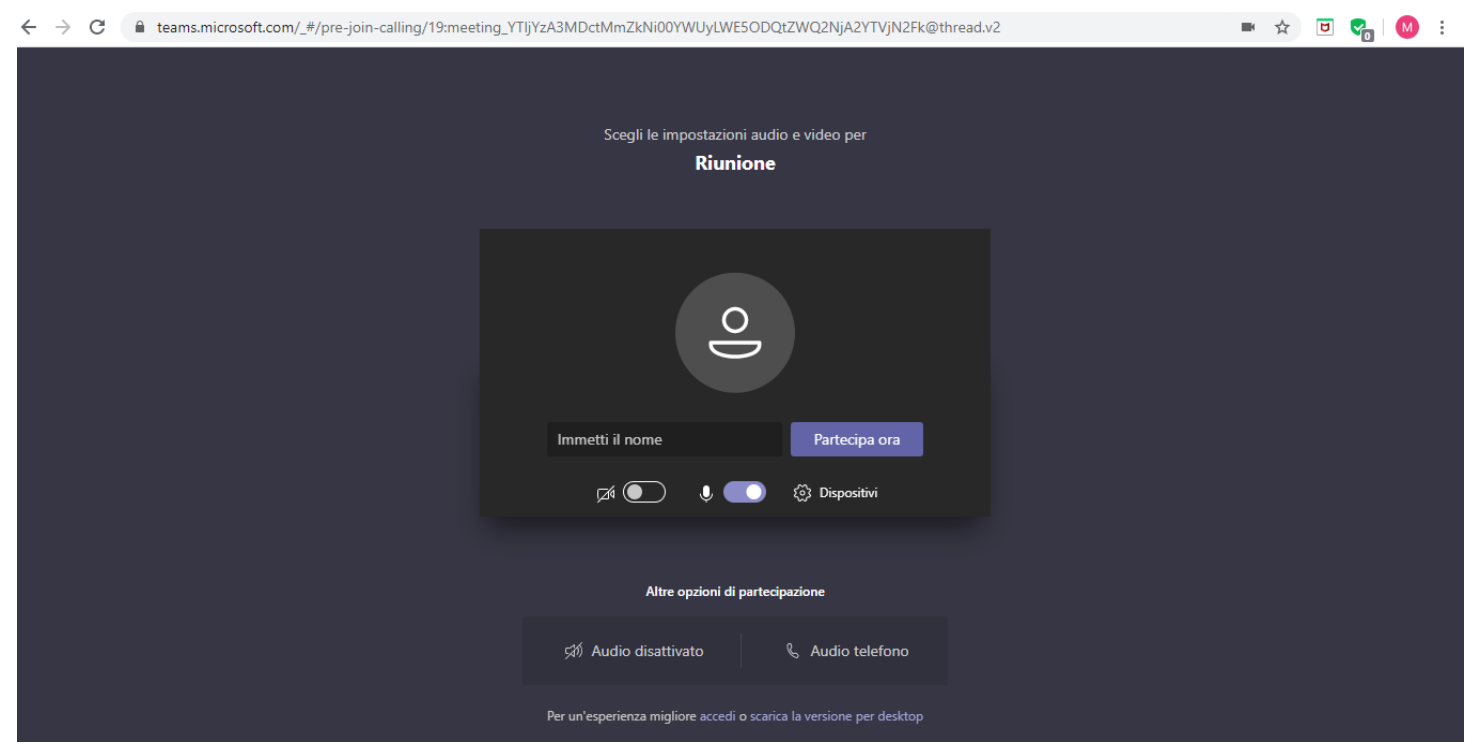

Figure 2. Microsoft Teams, how to enter the meeting

\section{CONCLUSION}

Most governments around the world have temporarily closed educational institutions in an attempt to contain the spread of the COVID-19 pandemic. COVID-19 has significantly affected all of our lives, but it is also challenging our ability to adapt and be resilient. The education sector is responding to quarantine with a sudden shift to online learning (Electronic Platform for Adult Learning in Europe). The present study, conducted by Tor Vergata University of Rome, represents an important insight for the emergency that the world is experiencing. Experts in the academic world must be encouraged to spread and share the strategies they are using to face these challenges. The advantage of international communication lies in the sharing that allows ever-higher standards in education. Authors found a lack of evidences in literature, especially related for the Italian context, which would have guided the structuring the online testing. Given the emergency we are facing, the authors believe that it is most important to inform the international-academic community about the strategies their university has chosen. Despite the lack of comments from the learners and a case study that records the effectiveness of online-testing methods, this paper only intended to describe the methodologies used by Tor Vergata University of Rome. In conclusion, this paper represents a first step in the dissemination and sharing, at an academic level, of how to face the current challenges in teaching. Further studies suggested by the authors of this paper include the organization of consensus workshops or consensus conferences especially on the topic of internship exams at national and international level. Intraprofessional consensus meeting, world cafè and qualitative analysis could represent an excellent way to identify and appraise experts' relevant consensus statements according to health professionals Core Curriculum and Core Competence.

\section{REFERENCES}

Directorial Decree n.3478 of April 14, 2020. Document of the Minister of University and Research Gaetano Manfredi on post lockdown. Available at: https://miur.gov.it/web/guest/-/decreto-direttoriale-n-3478-del-14-aprile-2020 (Accessed: 26 April 2020)

Electronic Platform for Adult Learning in Europe. COVID-19 is reviving the need to explore online teaching and learning opportunities. 24/ March 2020. Available at: https://epale.ec.europa.eu/en/blog/covid-19-reviving-need-exploreonline-teaching-and-learning-opportunities (Accessed: 26 April 2020) 
European Commission/EACEA/Eurydice, 2018. The European Higher Education Area in 2018: Bologna Process Implementation Report. Luxembourg: Publications Office of the European Union. Available at https://eacea.ec.europa.eu/national-policies/eurydice/sites/eurydice/files/bologna_internet_0.pdf (Accessed: 26 April 2020)

Farina I. et al, 2019. High-Fidelity Simulation Type Technique Efficient for Learning Nursing Disciplines in the Courses of Study: An Integrative Review. In: Methodologies and Intelligent Systems for Technology Enhanced Learning, 9th International Conference, Workshops. Avila, Spain

Galeoto G. et al, 2019 a. The Use of a Dedicated Platform to Evaluate Health-Professions University Courses. In book: Methodologies and Intelligent Systems for Technology Enhanced Learning, 8th International Conference. Toledo, Spain.

Galeoto G. et al, 2019 b. Evaluation of the Disciplinary Competences of the Students of the Bachelor's Degree in Physiotherapy at "Sapienza" University of Rome Through the TECO: A Cross-Sectional Study. In book: Learning Technology for Education Challenges. Zamora, Spain.

Guidelines for the final test of the Degree Courses belonging to the classes of Health Professions. Ministerial Decree 19 February 2009 Official Journal 25 May 2009, n.119. Available at https://www.fnopi.it/wpcontent/uploads/DM190209.pdf (Accessed: 26 April 2020)

Ministerial circular of 30 September 2016. operational indications about the final test of the courses related to the degree classes for the professions. Available at https://translate.google.com/\#view=home\&op=translate\&sl=it\&tl=en\&text=indicazioni $\% 20$ operative $\% 20$ circa $\% 201 \mathrm{a}$ $\% 20$ prova \%20finale \%20dei\%20corsi\%20afferenti\%20alle\%20classi\%20di\%20laurea\%20per\%20le\%20professioni $\% 20$ sanitarie (Accessed: 26 April 2020)

Paterniani A. et al, 2019. Electronic Test of Competence Administration: Qualitative Evaluation of Students' Satisfaction on Telematic Platform a Cross Sectional Study. In: Methodologies and Intelligent Systems for Technology Enhanced Learning, 9th International Conference, Workshops. Avila, Spain

The United Nations Educational, Scientific and Cultural Organization (UNESCO). Distance learning solutions. 2020. Available at: https://en.unesco.org/covid19/educationresponse/solutions (Accessed: 26 April 2020)

World Health Organisation, Coronavirus disease 2019 (COVID-19) Situation Report 46, 2020 